\title{
Aortic regurgitation associated with hypertrophic cardiomyopathy: a colour Doppler echocardiographic study
}

\author{
TAKAHIRO SHIOTA, TSUGUYA SAKAMOTO, KATSU TAKENAKA, \\ KEIKO AMANO, YOSHIYUKI HADA, ICHIRO HASEGAWA, JUN-ICHI SUZUKI, \\ HISAKO TAKAHASHI, TSUNEAKI SUGIMOTO
}

From the Second Department of Internal Medicine, Faculty of Medicine, University of Tokyo, Tokyo, Japan

SUMMARY The frequency, severity, and cause of aortic regurgitation were assessed by colour Doppler and cross sectional echocardiography in 87 patients (mean (SD) age 57 (12) years) with hypertrophic cardiomyopathy, and 48 age matched controls (57 (8) years). Aortic regurgitant murmurs were recorded in only three of 87 patients and in none of the controls. Colour Doppler echocardiography showed an aortic regurgitant signal in $20(23 \%)$ of the patients and three $(6 \%)$ of the 48 controls. The colour Doppler signals typical of aortic regurgitation were limited to the left ventricular outflow tract. There were no significant differences between patients with hypertrophic cardiomyopathy with and without aortic regurgitation in terms of age ( 59 years $v 56$ years), blood pressure (140/84 mm Hg $v 136 / 80 \mathrm{~mm} \mathrm{Hg}$ ), aortic diameter (34 $\mathrm{mm} v 33 \mathrm{~mm}$ ), or frequency of calcification of the aortic valve $(15 \% v 10 \%)$ and of systolic anterior motion of the mitral valve with mitral-septal contact (25\% $v 16 \%$ ). On cross sectional echocardiograms, the degree of septal protrusion into the left ventricular outflow tract during systole was significantly more prominent (15 $v 10 \mathrm{~mm}$ ), and the portion of the basal septum that protruded most deeply into the left ventricular outflow tract was significantly closer to the aortic annulus in patients with aortic regurgitation than in those without it $(11 v 14 \mathrm{~mm})$.

Mild aortic regurgitation was found in almost a quarter of patients with hypertrophic cardiomyopathy. The regurgitation was related to the morphological abnormality of the left ventricular outflow tract.

In hypertrophic cardiomyopathy, aortic regurgitation has long been thought to be rare. Before the era of echocardiography, only a few reports reported such as association ${ }^{12}$ and we had treated only one patient with both conditions. In this patient an aortic regurgitant murmur developed gradually. Even now that echocardiography is widely used there are still a few reports of such cases ${ }^{34}$ and even fewer reports of the incidence and cause of aortic regurgitation in patients with hypertrophic cardiomyopathy..$^{5}$ We assessed the frequency, severity, and cause of aortic regurgitation in patients with hypertrophic cardiomyopathy by cross sectional and colour Doppler echocardiography.

Requests for reprints to Dr Takahiro Shiota, Second Department of Internal Medicine, Faculty of Medicine, University of Tokyo, Hongo 7-3-1, Bunkyo-ku, Tokyo 113, Japan.

Accepted for publication 11 April 1989

\section{Patients and methods}

SELECTION OF PATIENTS

We evaluated 91 consecutive patients with hypertrophic cardiomyopathy in the Second Department of Internal Medicine, University of Tokyo, between January 1985 and May 1987. The diagnosis of hypertrophic cardiomyopathy was made in each patient by the echocardiographic visualisation of a non-dilated hypertrophic left ventricle and asymmetrical septal hypertrophy without any other known causes of hypertrophy. ${ }^{6}$ In all 91 patients, the interventricular septal thickness was more than $15 \mathrm{~mm}$ and the ratio of the septal thickness to the posterior wall thickness in diastole was greater than 1.3. One patient with symmetrical hypertrophy and one patient with apical hypertrophy were not included in the study group because of this diagnostic criteria. Four patients with apical hypertrophy, 
however, were included in the series because they had additional septal hypertrophy. Of 91 patients, two elderly women and two middle aged men were excluded because of inadequate colour flow patterns. We report on the remaining 87 patients with hypertrophic cardiomyopathy (63 men and 24 women, mean age 57 (12) years and 48 age matched controls ( 32 men and 16 women (57 (8) years)). None of the controls had a history of cardiac disease or systemic hypertension or were on medication at the time of study. They all had a normal 12 lead electrocardiogram, normal chest $x$ ray films, and normal physical findings.

\section{PHONOCARDIOGRAPHY}

Careful auscultation was performed to detect an aortic regurgitant murmur in each subject before the phonocardiographic examination. The auscultatory findings were confirmed by recording a high-pitched diastolic murmur at the point of maximum intensity with a high quality multichannel phonocardiograph or Siemens Mingograph 82.

\section{COLOUR DOPPLER ECHOCARDIOGRAPHY}

Colour Doppler, cross sectional, and $M$ mode echocardiographic examinations were performed with Aloka SSD 880, 860, or 870 with 2.5 or $3.5 \mathrm{MHz}$ transducers. Subjects were routinely studied in the left lateral position. The aortic regurgitant jet was sought on multiple planes in each subject, including parasternal long axis and short axis and apical long axis four chamber views. In each view, the transducer was carefully oriented to show maximally the regurgitant jets. Aortic regurgitation was considered to be present when an abnormal diastolic flow originating from the aortic valve was visualised in the left ventricle. Diastolic flow was identified as abnormal either because there was flow in an abnormal direction (that is, away from the aortic valve during diastole) or because of a mosaic pattern indicating turbulent flow.

\section{CROSS SECTIONAL BCHOCARDIOGRAPHY}

On cross sectional echocardiograms, calcification of the aortic valves and systolic anterior motion of the mitral valve with mitral-septal contact were sought on multiple planes.

MEASUREMENTS OF $D_{1}$ AND $D_{2}$ (fig 1 )

On the parasternal long axis view in systole, a line connecting the two points of the origin of the aortic valve was used to locate the plane of the aortic annulus $\left(A-A^{\prime}\right)$. From the point of right coronary cusp origin (A), a line (B) was drawn along the aortic long axis which was vertical to the line of the aortic annulus $\left(A-A^{\prime}\right)$. The distance $\left(D_{1}\right)$ from the point of

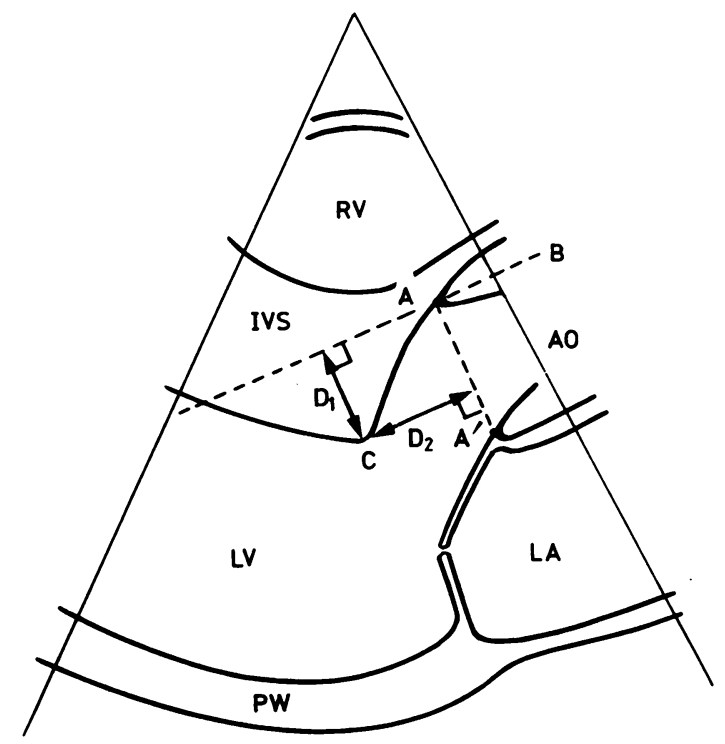

Fig 1 Measurements of $D_{1}$ and $D_{2}$. On the parasternal long axis view in systole, a line connecting the two points of the origin of the aortic valve was used to locate the plane of the aortic annulus $\left(A-A^{\prime}\right)$. From the point of right coronary cusp origin $(A)$, a line $(B)$ was drawn along the aortic long axis which was vertical to the aortic annulus $\left(A-A^{\prime}\right)$. The distance $\left(D_{1}\right)$ from the point at which the interventricular septum protruded most deeply into the left ventricular outflow tract $(C)$ to the line $B$ was measured, as was the distance $\left(D_{2}\right)$ from the point $C$ to the aortic annulus line $\left(A-A^{\prime}\right)$. AO, aorta; IVS, interventricular septum; $L A$, left atrium, $L V$, left ventricle; $P W$, left ventricular posterior wall; $R V$, right ventricle.

the interventricular septum that protruded most deeply into the left ventricular outflow tract $(C)$ to the line $B$ was measured. The distance $\left(D_{2}\right)$ from the point $C$ to the aortic annulus line $\left(A-A^{\prime}\right)$ was also measured. Then $D_{1}$ was calculated as a percentage of $D_{2}$.

\section{MODE ECHOCARDIOGRAPHY}

Standard $M$ mode echocardiograms were recorded from the parasternal window on a strip chart at a paper speed of 50 or $100 \mathrm{~mm} / \mathrm{s}$ according to the recommendations of the American Society of Echocardiography. ${ }^{7}$ The following were measured: left ventricular end diastolic dimension, left ventricular end systolic dimension, end diastolic left ventricular posterior wall thickness, end diastolic interventricular septal thickness, aortic root diameter, and left atrial dimension. The ratio of end diastolic interventricular septal thickness to end diastolic left ventricular posterior wall thickness was calculated. 


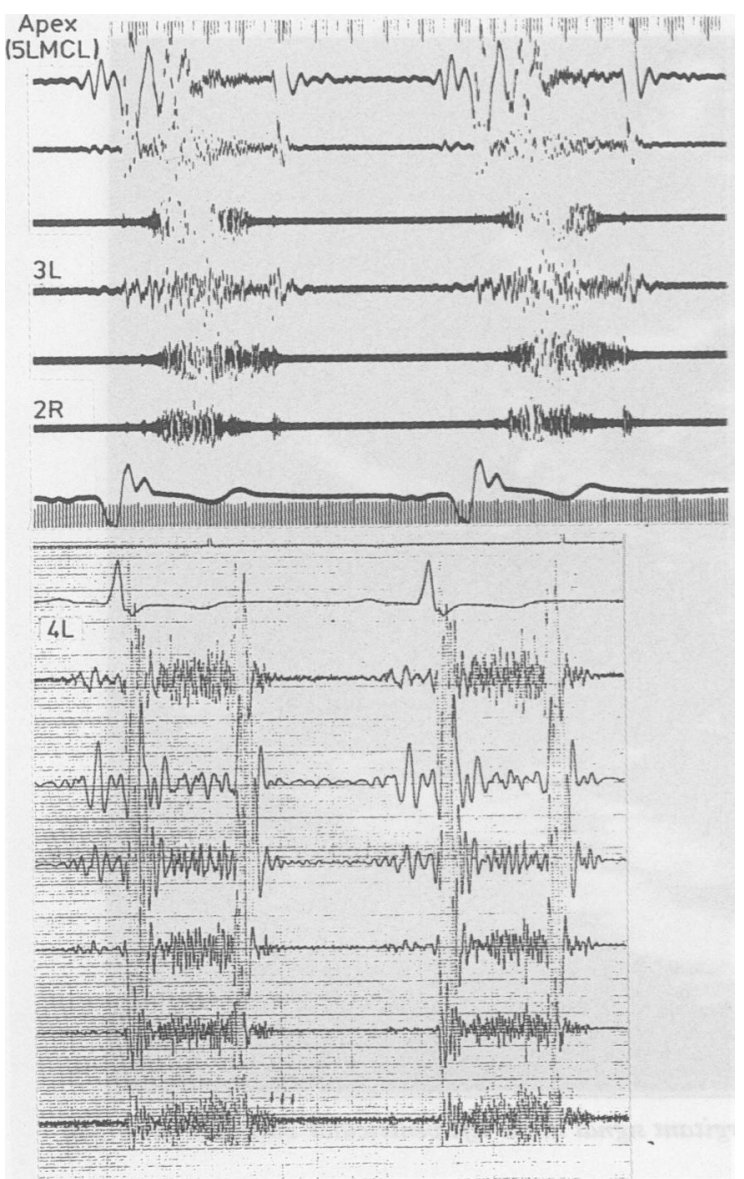

Fig 2 Phonocardiograms of a patient with hypertrophic cardiomyopathy. An aortic regurgitant murmur was not detected at the age of 15 (upper panel), while high-pitched diastolic murmur was recorded at the fourth left intercostal space at the age of 30 (lower panel).

Blood pressure was measured at the time of the study by the standard cuff method with an appropriately sized cuff.

\section{STATISTICAL ANALYSIS}

Data were expressed as mean (SD). Group data were compared by Student's $t$ test or a $\chi^{2}$ test. Variability was expressed as the percentage error of each measurement and was determined as the difference between the two observations divided by the mean value of the two observations. A probability (p) value of $<\mathbf{0 . 0 5}$ was regarded as statistically significant.

\section{Results}

AN ILLUSTRATIVE CASE

A 15 year old boy with hypertrophic obstructive cardiomyopathy was referred to our department in 1971 because of an illness discovered in 1964 . He had a loud systolic ejection murmur with late peak intensity and fourth heart sound and no diastolic regurgitant murmur in the initial phonocardiogram (fig 2, upper panel). A high pitched diastolic murmur gradually appeared during the next 10 years. Phonocardiography showed the diastolic murmur in 1986 (fig 2, lower panel). An aortic regurgitant signal was recognised by colour Doppler echocardiography (fig 3).

\section{FREQUENCY OF AORTIC REGURGITATION IN PATIENTS WITH HYPERTROPHIC}

CARDIOMYOPATHY AND IN CONTROLS

An aortic regurgitant murmur was heard or recorded in only three $(3 \%)$ of 87 patients with hypertrophic cardiomyopathy and in none in the controls. Colour Doppler echocardiography showed aortic regurgitant signals in $20(23 \%)$ of 87 patients with hypertrophic cardiomyopathy and in three $(6 \%)$ of the 48 controls. The colour Doppler signals of aortic regurgitation were restricted to the left ventricular outflow tract in patients with hypertrophic cardiomyopathy and the controls.

\section{COMPARISON OF PATIENTS WITH}

HYPERTROPHIC CARDIOMYOPATHY WITH

AORTIC REGURGITATION AND WITHOUT (table)

There were no statistically significant differences

Table Comparison of clinical and echocardiographic data in patients with hypertrophic cardiomyopathy with aortic regurgitation and without

\begin{tabular}{|c|c|c|c|c|c|}
\hline \multirow[b]{2}{*}{$\begin{array}{l}\text { n } \\
\text { Age (yr) } \\
\text { sBP (mm Hg) } \\
\text { dBP (mm Hg) } \\
\text { AOD (mm) } \\
\text { LAD (mm) } \\
\text { LVDs (mm) } \\
\text { LVDd (mm) } \\
\text { IVS (mm) } \\
\text { LVPW (mm) } \\
\text { IVS/LVPW } \\
\text { Cal of AV } \\
\text { SAM } \\
D_{1}(\mathbf{m m}) \\
D_{2}(\mathbf{m m}) \\
D_{1} / \mathbf{D}_{2}(\%)\end{array}$} & \multicolumn{2}{|c|}{ HCM with $A R$} & \multicolumn{2}{|c|}{ HCM without $A R$} & \multirow[b]{2}{*}{$\begin{array}{l}\text { pvalue } \\
\text { NS } \\
\text { NS } \\
\text { NS } \\
\text { NS } \\
\text { NS } \\
\text { NS } \\
\text { NS } \\
\text { NS } \\
\text { NS } \\
\text { NS } \\
\text { NS } \\
\text { NS } \\
\text { NS } \\
<0.001 \\
<0.001 \\
<0.001\end{array}$} \\
\hline & $\begin{array}{c}20 \\
59 \\
140 \\
84 \\
34 \\
42 \\
29 \\
46 \\
21 \\
13 \\
1 \cdot 6 \\
3 / 20 \\
5 / 20 \\
15 \\
11 \\
165\end{array}$ & $\begin{array}{l}(13) \\
(22) \\
(19) \\
(5 \cdot 2) \\
(6 \cdot 3) \\
(6 \cdot 4) \\
(6 \cdot 0) \\
(5 \cdot 0) \\
(3 \cdot 0) \\
(0 \cdot 2) \\
(15 \%) \\
(25 \%) \\
(5 \cdot 0) \\
(6 \cdot 1) \\
(72)\end{array}$ & $\begin{array}{c}67 \\
56 \\
136 \\
80 \\
33 \\
43 \\
26 \\
44 \\
21 \\
12 \\
1 \cdot 7 \\
7 / 68 \\
11 / 68 \\
10 \\
14 \\
74\end{array}$ & $\begin{array}{c}(13) \\
(24) \\
(14) \\
(3.6) \\
(6.0) \\
(5.7) \\
(5 \cdot 2) \\
(5 \cdot 3) \\
(2 \cdot 2) \\
(0.4) \\
(10 \%) \\
(16 \%) \\
(3.7) \\
(3.9) \\
(31)\end{array}$ & \\
\hline
\end{tabular}

$A R$, aortic regurgitation; $A O D$, aortic root diameter; Cal of $A V$, calcification of the aortic valve; $\mathrm{dBP}$, diastolic blood pressure; LAD, maximum left atrial size; LVDd, end diastolic left ventricular dimension; LVDs, end systolic left ventricular dimension; LVPW, end diastolic left ventricular posterior wall thickness; HCM, hypertrophic cardiomyopathy; IVS, end diastolic ventricular septal thickness; SAM, systolic anterior motion of the mitral valve with mitral-septal contact; $\mathrm{SBP}$, systolic blood pressure; $D_{1}$ and $D_{2}$ are defined in fig 1 . 


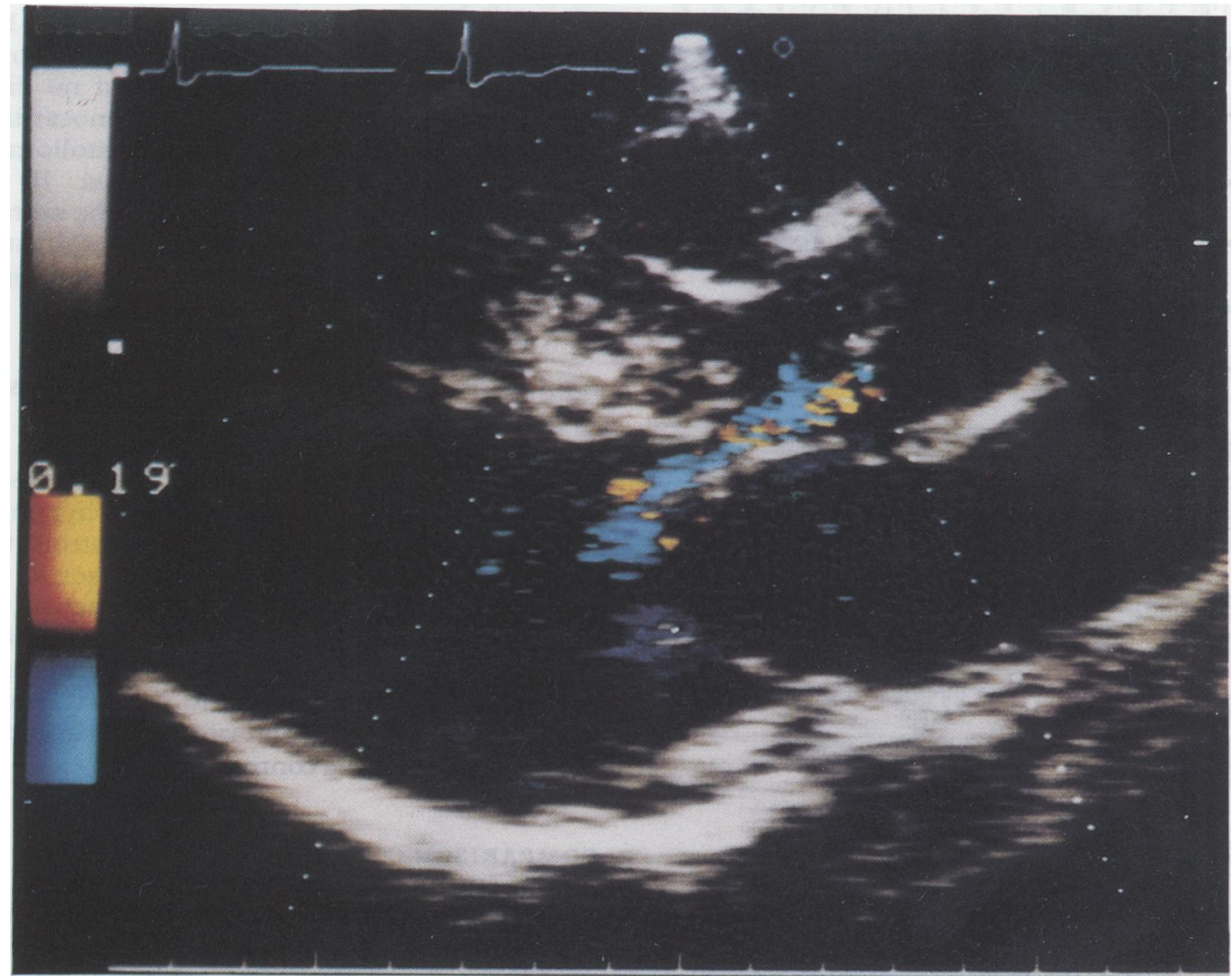

Fig 3 Colour Doppler echocardiogram showing aortic regurgitant signal in the left ventricular outflow tract in the same patient as fig 2.

between most variables in patients with hypertrophic cardiomyopathy who had aortic regurgitation and those who did not. These were age, blood pressure, left ventricular end diastolic dimension, left ventricular end systolic dimension, end diastolic left ventricular posterior wall thickness, end diastolic interventricular septal thickness, the ratio of end diastolic interventricular septal thickness to end diastolic left ventricular posterior wall thickness, aortic root diameter, left atrial dimension, or frequency of aortic valve calcification or systolic anterior motion of the mitral valve with mitral-septal contact.

In the parasternal long axis view, $D_{1}$ was significantly longer $(15(5.0) v 10(3.7) \mathrm{mm}, \mathrm{p}<0.001$, fig 4 left panel) and $\mathrm{D}_{2}$ was shorter $(11(6 \cdot 1) v 14(3.9)$ $\mathrm{mm}, \mathrm{p}<0.001$, fig 4 middle panel) in patients with aortic regurgitation than those without aortic regurgitation. The ratio of $D_{1}$ to $D_{2}$ was significantly greater in patients with aortic regurgitation than those without it $(165(72) v 74(31) \%, p<0.001$, fig 4 right panel). These data indicate that the basal septum protruded more into the left ventricular outflow tract, and the point of the septum that protruded most was closer to the aortic valve in patients with aortic regurgitation than in patients without it (fig 5).

\section{REPRODUCIBILITY OF MEASUREMENTS OF D} AND $\mathrm{D}_{2}$

Two independent observers repeated measurements of $D_{1}$ and $D_{2}$ to determine intraobserver and interobserver variability. Each observer measured $D_{1}$ and $\mathrm{D}_{2}$ using an appropriate still frame without knowledge of his previous measurement or that of the other observer. Mean percentage intraobserver variability was $2 \%$ for $D_{1}$ and $3 \%$ for $D_{2}$. The correlation coefficient for $D_{1}$ was 0.98 and for $D_{2}$ it was $\mathbf{0 . 9 7}$. Interobserver variability (and correlation coefficients) for $D_{1}$ and $D_{2}$ were $4 \%(0.93)$ and $5 \%$ $(0.88)$, respectively. Therefore, measurements of $D_{1}$ and $D_{2}$ can be performed with acceptable reproducibility. 

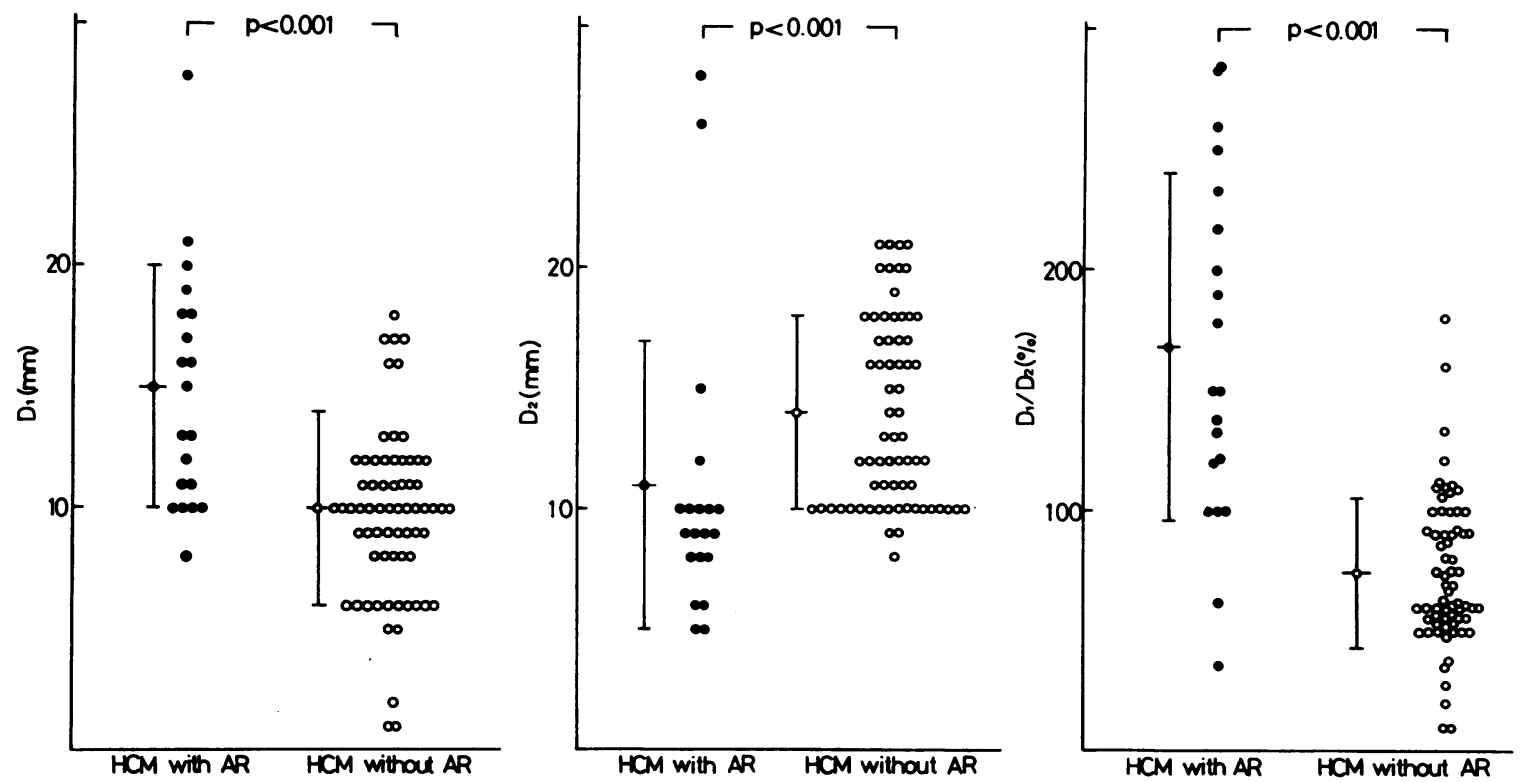

Fig $4 D_{1}, D_{2}$, and $D_{1} / D_{2}$ in patients with hypertrophic cardiomyopathy (HCM) who had aortic regurgitation (AR) and those who did not.

\section{Discussion}

\section{FREQUENCY AND SEVERITY OF AORTIC} REGURGITATION IN HYPERTROPHIC

\section{CARDIOMYOPATHY}

Teare and others have described diastolic murmurs in patients with hypertrophic cardiomyopathy. ${ }^{8-10}$ Most of these reports, however, dealt with diastolic rumbles, presystolic murmurs, and third or fourth sounds. A high-pitched diastolic murmur caused by

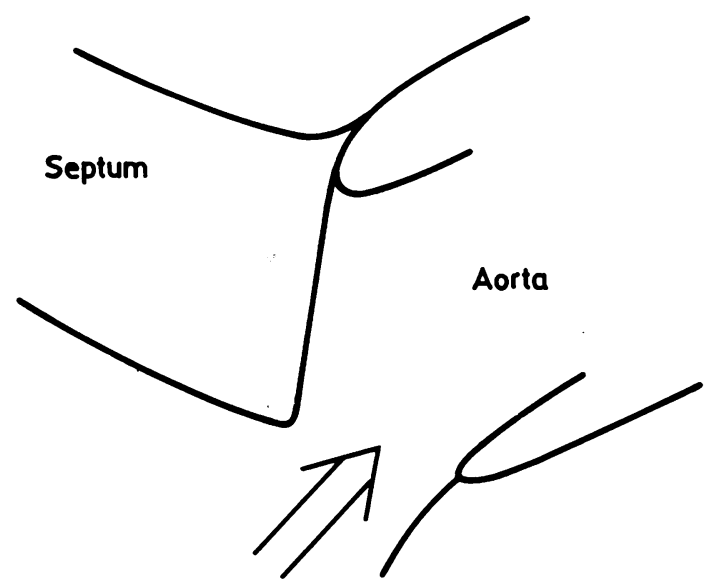

HCM with AR aortic regurgitation was rarely reported. Frank and Braunwald reported that seven of 126 patients with idiopathic hypertrophic cardiomyopathy had diastolic murmurs best heard at the apex in all. ${ }^{11}$

Barlow and Pocock described how aortic annular distortion caused by asymmetric myocardial hypertrophy led to aortic regurgitation in a few patients. The murmurs were soft and short and the regurgitation was slight. ${ }^{12}$ However, the prevalence was not analysed statistically.

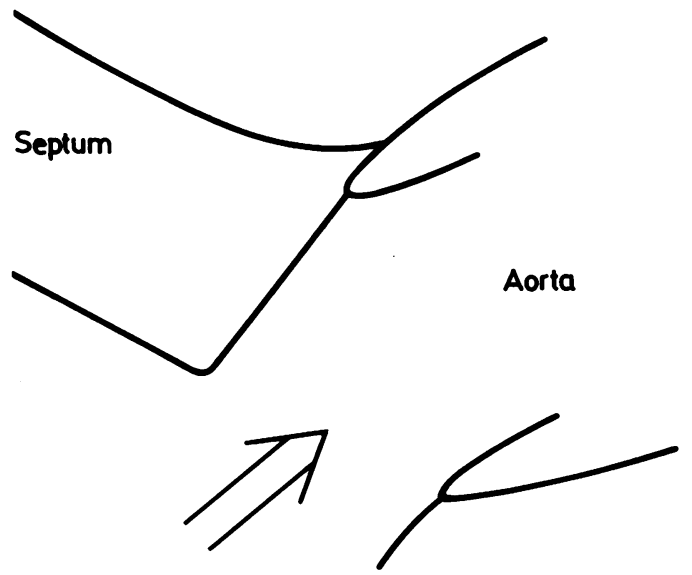

HCM without AR

Fig 5 Schematic model of the interventricular septum and aortic root based on the data of $D_{1}$ and $D_{2}$. The basal septum protruded more deeply into the left ventricular outflow tract and the point of the septum that protruded most deeply into the left ventricular outflow tract was closer to the aortic valve in patients with aortic regurgitation than in those without it. Arrows indicate the direction of ejection flow. 
In the present study, colour Doppler echocardiography showed that aortic regurgitation was not uncommon in patients with hypertrophic cardiomyopathy. Signals of aortic regurgitation were limited to the left ventricular outflow tract, suggesting that the degree of the regurgitation was mild. This is probably the reason why this association has rarely been detected by auscultation, phonocardiography, or conventional echocardiography. In 1987 Theard et al reported that conventional pulsed Doppler echocardiography detected mild aortic regurgitation in nearly a third of patients with hypertrophic cardiomyopathy. ${ }^{5}$

\section{POSSIBLE CAUSE OF AORTIC REGURGITATION IN PATIENTS WITH HYPERTROPHIC \\ CARDIOMYOPATHY}

Barlow and Pocock suggested that morphological abnormality, that is, distortion of the aortic annulus caused by asymmetrical myocardial hypertrophy can result in aortic regurgitation. ${ }^{12}$ The data on $D_{1}$ and $D_{2}$ and the ratio of $D_{1}$ and $D_{2}$ in the present study support this hypothesis, because the distortion of the aortic annulus is thought to be more pronounced in patients with aortic regurgitation than those without it.

The presence of systolic anterior motion of the mitral valve was not associated with aortic regurgitation in patients with hypertrophic cardiomyopathy. This is because the point of obstruction formed by the systolic anterior motion of the mitral valve is far from the aortic root and the impact of the jet stream to the aortic root may be weak. Yock et al recently reported that the high velocities of jets in the left ventricular outflow tract of patients with hypertrophic obstructive cardiomyopathy were generally not conducted to the aorta. ${ }^{13}$

There was no significant difference in ejection flow velocity immediately below the aortic valve measured by pulsed Doppler echocardiography between the patients with hypertrophic cardiomyopathy who had aortic regurgitation and those who did not. An eccentrically directed ejection flow caused by the interventricular septum that protruded deeply into the left ventricular outflow tract rather than flow velocity itself might be related to the cause of aortic regurgitation.

Although the exact cause of aortic regurgitation is uncertain, the morphological abnormality of the aortic root was related to the regurgitation.

\section{References}

1 Pare JAP, Fraser RG, Pirozynski WJ, Shanks JA, Stubington D. Hereditary cardiovascular dysplasia: a form of familial cardiomyopathy. Am J Med 1961;31: 37-67.

2 Hansen P, Davidson HG, Fabricius J. Subvalvular aortic stenosis of muscular type. Acta Med Scand 1962;171:743-51.

3 Nagata S, Nakanishi N, Ohe T, et al. Masking of obstructive signs in hypertrophic obstructive cardiomyopathy in the presence of left ventricular volume overload and its pathophysiological implications: a case report. J Cardiogr 1982;12:1033-42.

4 Sasson Z, Wigle ED. Aortic regurgitation following surgery for muscular subaortic stenosis [Abstract]. Circulation 1985;72(suppl III):1580.

5 Theard MA, Bhatia SJS, Plappert T, Sutton MSJ. Doppler echocardiographic study of the frequency and severity of aortic regurgitation in hypertrophic cardiomyopathy. Am J Cardiol 1987;60:1143-7.

6 Maron BJ, Epstein SE. Hypertrophic cardiomyopathy: a discussion of nomenclature. Am J Cardiol 1979;43: 1242-4.

7 Sahn DJ, DeMaria A, Kisslo J, Weyman A. The committee on $\mathrm{M}$-mode standardization of the American Society of Echocardiography. Recommendations regarding quantitation in M-mode echocardiography: results of a survey of echocardiographic measurements. Circulation 1978;58:1072-83.

8 Teare D. Asymmetrical hypertrophy of the heart in young adults. Br Heart J 1958;20:1-8.

9 Sakamoto T, Hayashi T, Inoue $K$, Ito U, Matsuhisa $M$. Mitral opening sound and isovolumic relaxation period in idiopathic hypertrophic subaortic stenosis. Cardiovasc Sound Bull 1973;3:83-92.

10 Smith MR, Agruss NS, Levenson NI, Adolph RJ. Nonobstructive hypertrophic cardiomyopathy mimicking mitral stenosis. Am J Cardiol 1975;35: 89-96.

11 Frank S, Braunwald E. Idiopathic hypertrophic subaortic stenosis. Clinical analysis of 126 patients with emphasis on the natural history. Circulation 1968;37: 759-88.

12 Barlow JB, Pocock WA. Hypertrophic cardiomyopathy. In: Barlow JB, ed. Perspectives on the mitral valve: conditions involving the mitral valve mechanism. Philadelphia: FA Davis, 1987:198-211.

13 Yock PG, Hatle L, Popp RL. Patterns and timing of Doppler-detected intracavitary and aortic flow in hypertrophic cardiomyopathy. J Am Coll Cardiol 1986;8:1047-58. 